\title{
Global Cartels, Leniency Programs and International Antitrust Cooperation
}

\author{
Jay Pil Choi \\ Heiko Gerlach
}

CESIFO WORKING PAPER NO. 3005

CATEGORY 11: INDUSTRIAL ORGANISATION

MARCH 2010

An electronic version of the paper may be downloaded

- from the SSRN website:

- from the RePEc website:

- from the CESifo website:

www.SSRN.com

Www.RePEc.org

www.CESifo-group.org/wp 


\title{
Global Cartels, Leniency Programs and International Antitrust Cooperation
}

\begin{abstract}
In this paper we analyze cartel formation and self-reporting incentives when firms operate in several geographical markets and face antitrust enforcement in different jurisdictions. We are concerned with the effectiveness of leniency programs and the benefits of international antitrust cooperation between agencies. When international antitrust prosecution is uncoordinated, multi-market contact allows firms to reduce the amount of self-reporting in equilibrium and sustain cartels more effectively. We then discuss the effects of information sharing among antitrust authorities as a function of how much and which type of information is exchanged. We show that extensive information sharing might have an adverse effect on self-reporting by cartel members.
\end{abstract}

JEL-Code: L13, L41, D43.

Keywords: cartel formation, multi-market contact, leniency programs, international antitrust cooperation.

Jay Pil Choi

Michigan State University

choijay@msu.edu
Heiko Gerlach

University of Auckland

h.gerlach@auckland.ac.nz

March 2010

We would like to thank participants at various conferences and seminars for their comments. Gerlach acknowledges the support of the Barcelona GSE Research Network and the Government of Catalonia. 


\section{Introduction}

Global cartels have become pervasive in recent decades victimizing both businesses and consumers around the world. Between 1990 and 2008, there were 516 official investigations of suspected international cartels. The total affected sales by these cartels is estimated at US\$16 Trillion nominal (Connor, 2009). As a response national antitrust authorities are stepping up their effort to coordinate international cartel prosecution $\bigsqcup^{1}$ For example, Scott Hammond (2003), Director of the DOJ Antitrust Division, emphasizes the need for local antitrust authorities to share case information at various stages of the cartel prosecution process:

“... There is now a willingness and a desire among competition authorities to work together against a common enemy - hardcore cartels - that is unmatched at any time in history... We must share leads and information. We must coordinate our investigative strategies. We must gain access to subjects, evidence and witnesses that are located outside our borders.".

However, he also admits that there might be limits to information sharing with other antitrust authorities, particularly, when it concerns information obtained during leniency program applications:

“... the Antitrust Division has adopted a policy of not disclosing to foreign authorities, information obtained from a leniency applicant unless the leniency applicant agrees first to the disclosure. This policy gives leniency applicants a measure of control over investigations that might strike some as problematic. However, the confidentiality policy is a necessary inducement to encourage leniency applications."

This paper explores the relationship between international antitrust coordination, cartel formation and the effectiveness of leniency programs. We are interested in addressing the issue of how much information and which type of information should antitrust authorities

\footnotetext{
${ }^{1}$ Over the last two decades the US DOJ Antitrust Division has entered bilateral antitrust cooperation agreements with Brazil, Canada, European Union, Germany, Israel, Japan and Mexico. These agreements foster investigative and technical assistance but do not allow access to confidential information from other agencies. A formal way for US agencies to obtain such material are agreements negotiated under the International Antitrust Enforcement Assistance Act (IAEAA). The Mutual Legal Assistance Treaties (MLAT) with Australia, Canada, EU and Japan offer a separate formal mechanism under which assistance in criminal antitrust matters are available, including investigative assistance and access to confidential information. See chapter 4 of ICPAC report for more details.
} 
share in their fight against global cartels. To this effect, we consider a repeated price game with two global firms operating in two different jurisdictions. In each jurisdiction a local antitrust authority enforces cartel laws using procedural investigations and a leniency program which offers antitrust immunity for the first firm to self-report a cartel. We compare three different scenarios as a function of how much and which type of information the antitrust authorities share. Our benchmark is a setting where antitrust authorities are uncoordinated and not sharing any information relating to their cartel investigations. In the second scenario antitrust authorities agree to share cartel leads and all information obtained during their investigations. However, they grant firms confidentiality on all information obtained during the admission to the leniency program. Finally, we consider extensive information sharing, in which antitrust authorities share cartel leads, information from procedural investigations and from leniency applications.

We show that when local antitrust authorities are not sharing any information, multinational firms self-report less often and find it easier to sustain a cartel compared to strictly local firms. In other words, multi-market contact reduces the effectiveness of leniency programs and fosters collusion. Bernheim and Whinston (1990) show that multi-market contact allows firms to pool their incentives and transfer slack collusive rents from one market to another market where collusion is harder to sustain. This increases global cartel formation when firms operate in asymmetric markets. In our set-up markets are ex ante symmetric but multi-market contact still raises global cartel profits and fosters collusion. The reason is that multinational firms can use self-reporting strategies which introduce market asymmetry at the interim stage and allow incentive pooling. Consider a situation in which after the start of an investigation, local firms are collectively better off not to self-report but each has a unilateral incentive to deviate and apply for leniency. When firms are global and investigations in both jurisdictions open, we show that firms optimally self-report to exactly one antitrust authority and take the risk of being prosecuted in the other market. This enables global firms to shift collusive rent from the market with the self-reported cartel to the market where they face prosecution and lower expected profits. In other words, global firms sustain a strategy of partial self-reporting whereas local firms would report all active cartels. This yields higher global profits and allows for more cartel formation.

When antitrust authorities cooperate by sharing leads and case information but keep leniency program information confidential, two benefits arise. Cartels face a higher probability of detection and a higher probability of successful prosecution. Compared to uncoordinated antitrust enforcement, this unambiguously increases self-reporting and reduces the scope for cartel formation. For low prosecution probabilities and fine-profit ratios, firms never self-report. If these parameters are sufficiently high, firms self-report in both juris- 
dictions. While for intermediate values, firms use the confidentiality policy of the local leniency program and report to exactly one antitrust authority. Finally, we consider the extensive information sharing scenario such that antitrust authorities refrain from confidentiality agreements with leniency applicants. In this case, an equilibrium in which firms report to both antitrust authorities dominates the equilibrium with only one leniency application. However, if the prosecution probability is low-to-medium and the fine-profit ratio sufficiently small, then not self-reporting in any jurisdiction dominates self-reporting both cartels. Hence, with confidentiality agreements firms would self-report in one market whereas with information sharing firms are not reporting at all. By contrast, if the prosecution probability is medium-to-high and the fine-profit ratio sufficiently large, then firms apply for leniency in both jurisdiction whereas they self-report to exactly one agency when a confidentiality agreement is in place.

This paper builds on a growing literature on the effects of leniency programs. However, none of these papers considers multi-market contact and international antitrust cooperation. The set-up of our analysis is close to Motta and Polo (2003) who analyze leniency programs that allow firms to receive fine reductions for self-reporting a cartel when an investigation opens. They show that self-reporting might arise in equilibrium and reduce the antitrust authority's cost of cartel prosecution. At the same time, leniency programs might have a pro-collusive effect by reducing the expected cost of antitrust prosecution. This might increase ex ante cartel formation. Aubert, Kovacic and Rey (2006) consider an environment where the probability of conviction is constant over time and propose introducing rewards for informants on top of amnesty from fines. They also discuss leniency and reward for individual employees of cartel members for self-reporting cartels. This requires that colluding firms must compensate employees to deter them from reporting the cartel which in turn reduces the benefits of cartel formation. Harrington (2008) investigates leniency programs in a richer environment in which the probability of conviction is distributed according to a continuous distribution function. This allows to identify a further effect of leniency programs. A more lenient program might induce firms to switch from an equilibrium with no self-report to an equilibrium in which all firms self-report. Thus, although the antitrust fine for the first firm to come forward is reduced, the expected antitrust penalty conditional on being first increases and reduces the gains from collusion. We use a simpler model and focus on the effect of multi-market contact and international cooperation in antirust enforcement $2^{2}$

\footnotetext{
${ }^{2}$ There is also growing empirical literature. Miller (2009) is one of the first papers to provide evidence that leniency programs might have positive effects in practice. His study of US cartels between 1985 and 2005 shows that the number of cartel discoveries significantly increased around the date of the introduction of the DOJ's leniency program in 1993 and then sharply dropped. Such a pattern is at least consistent
} 
Our paper is also related to the literature on cartel formation with multi-market contact initiated by the seminal paper of Bernheim and Whinston (1990) discussed above. In particular, this analysis is related to Choi and Gerlach (2009a) who explore the benefits of international antitrust cooperation when global firms operate in markets linked by a negative demand relationship. The demand linkage creates externalities via the prosecution efforts of local antitrust authorities. It is shown that uncoordinated local antitrust efforts might lead to too much or to too little antitrust enforcement from a global perspective $3^{3}$

The remainder of the paper is organized as follows. In section 2 , we set up the benchmark model without international antitrust cooperation. This case is analyzed in Section 3. In the following section we consider cartel formation with information sharing and leniency program confidentiality. In Section 5 we investigate the effects of extensive information sharing among antitrust authorities. The final section concludes.

\section{The Model}

We first introduce the benchmark model of international cartel formation when antitrust authorities are not cooperating.

Firms and Markets. Consider an industry with two firms selling a homogeneous product in two different countries. The firms are identical and produce with a constant marginal cost $c$. Demand in both countries is identical and equal to $D(p)$. Demand yields quasi-concave industry profits and a unique profit maximum $\pi$ in each country. Firms are engaged in a repeated price game in discrete time and maximize expected, discounted profits. Denote $0<\delta<1$ as the discount factor. In each period firms decide whether to collude or compete in the two markets. Deviations are met with optimal punishment strategies, i.e. the perfect equilibrium providing the lowest profits (Abreu, 1988). In our context, any deviation is punished with eternal reversion to competition in both markets. Thus, firms repeat the static Bertrand solution and receive continuation profits of zero in both markets.

Antitrust Enforcement. In each country cartel laws are enforced by a local antitrust authority (AA, henceforth) using procedural investigations and leniency programs for firms. There are three enforcement stages in the prosecution of cartels. First, price-fixing conspiracies need to be discovered. Second, discovered conspiracy schemes need to be prosecuted. Finally, successfully prosecuted cases need to be penalized to break up the existing cartels

with enhanced cartel detection and improved deterrence.

${ }^{3}$ Choi and Gerlach (2009b) use a more general framework which encompasses positive demand relationships as well. However, they are not considering antitrust coordination across markets and focus on characterizing dynamic cartel formation in the presence of exogenous antitrust enforcement. 
and deter the formation of future cartels. As pointed out by Harrington (2006), the role of antitrust authorities in the discovery stage has been minimal in that they are typically a passive agent that responds to complaints by disgruntled employees and suspicious customers who provide initial leads on price-fixing schemes. To reflect this reality, we assume that if a cartel exists, the local AA receives a lead on a cartel in its market with an exogenous probability of $\alpha(\geq 0)$ in each period $4^{4}$ This cartel lead probability is independent across markets and over time. Based on this initial suspicion, the AA opens an investigation. During an investigation firms can self-report their cartel activity and apply for admission to the leniency program of the local AA. We assume both AAs run the following leniency program. The first firm to come forward is rewarded by amnesty from antitrust fines. The second firm pays the maximum stipulated fine $F>0.5$ If no firm self-reports, the AA continues their investigation which leads to a successful prosecution with probability $\beta$. The parameter $\beta$ is among others a function of the resources available to the AA. In case of a successful prosecution the AA imposes the maximal stipulated fine $F$ on each cartel member ${ }^{6}$ Moreover, a successful prosecution - either by self-reporting or investigation implies antitrust compliance of firms in the local market for the current period.7 If an investigation remains inconclusive, the cartel case is closed and the AA only investigates the industry again if it receives a new cartel lead.

Throughout our analysis we restrict attention to situations in which the discount factor is sufficiently large and the probability of a cartel lead is sufficiently small such that

$$
\delta \geq \frac{3+\alpha}{4(1-\alpha)}
$$

This assumption makes sure that cartels always form when the antitrust fine is sufficiently low. Moreover, as will be seen below, it makes self-reporting constraints more important relative to price deviation constraints. Note that as $\alpha$ approaches zero, the minimum discount factor is $3 / 4$ and as $\delta$ goes to one A1 holds if $\alpha \leq 1 / 5$.

\footnotetext{
${ }^{4}$ Bryant and Eckart (1991) use a large sample of DOJ cases and find that the probability that a pricefixing conspiracy will be indicted in a given year is at most between 0.13 and 0.17 .

${ }^{5}$ This reflects the leniency program design of the US DOJ since 1993. Due to plea bargaining, firms who self-report after the first applicant might receive some reductions in exchange for guilty pleas. A lower reduction for the first firm or a higher reduction for the second firm would not alter the qualitative nature of our results. See OECD (2003) for an overview of leniency programs across countries. Spagnolo (2008) provides a general discussion of the economics of leniency programs.

${ }^{6}$ For example, the European Commission can impose a maximum amount of $10 \%$ of the company's total revenues in the year preceding the decision. In the U.S. the maximum fine for a company is the greatest of $\$ 100$ million, twice the gross gain to the cartel or twice the gross harm of the cartel.

${ }^{7}$ Extending compliance to say $T$ periods after prosecution would not change the qualitative nature of our results.
} 
Timing. We can summarize the timing of the repeated stage game as follows 8 (1) Firms decide whether to collude or not, (2) firms simultaneously set prices, (3) with probability $\alpha$ each local AA receives a cartel lead and opens an investigation, (4) firms simultaneously decide to apply for leniency to one, two AAs or not at all, (5) if firms do not self-report to a local AA, they are prosecuted with probability $\beta$ in this jurisdiction, (6) firms produce and receive their payoffs. We refer to this set-up as the benchmark model without cooperation among local AAs. We analyze the subgame-perfect equilibrium of this game in the next section.

Cooperation among the AAs. In sections 4 and 5 we consider two variants of this basic set-up to account for cooperation among local antitrust authorities. In particular, we are concerned with two different cooperation schemes for local AAs. First, we consider an information sharing agreement in which

(I-1) each local AA reports a cartel lead to the AA in the other country and (I-2) each local AA shares information obtained during its investigation with the AA in the other country.

The implication of $(I-1)$ in our set-up is that upon obtaining this information the partner AA is able to start an investigation in the same period even if it has not received a cartel lead on its own. This could be due to the fact that a cartel lead in one market raises the suspicion that the same firms might also cartelize the other market and this triggers the investigation. With respect to (I-2) we suppose that during a successful prosecution in one country, the local AA finds hard evidence of the cartel agreement in the other market. This evidence is sufficient for a successful prosecution in the other country even if the other AA was not successful with its own investigation.$^{9}$ We analyze the benchmark model with information sharing according to policies $(I-1)$ and $(I-2)$ in section 4 . In section 5 we consider a cooperation scheme of extensive information sharing in which the AAs agree to $(I-1),(I-2)$ and to policy

(I-3) each local AA shares information obtained within its leniency program.

\footnotetext{
${ }^{8}$ This timing is in line with the model of Motta and Polo (2003). Alternatively, one could assume a different relative timing of pricing and self-reporting or, allow pricing before and after self-reporting. This would change the incentive to deviate at the interim stages in all three information sharing regimes we analyze. It would, however, not affect the qualitative results of our analysis.

${ }^{9}$ For example, in Thermal Fax Paper and Disposable Plastic Dinnerware, US antitrust enforcers relied on evidence obtained through assistance from Canadian authorities in bringing these cases to their final disposition. In Thermal Fax Paper, the US and Canada coordinated their subpoena efforts and the US was able to convict the firms due to access to Canada's database of documents and information. In the Disposable Plastic Dinnerware, the US informed the Canadian authorities of the case and they conducted simultaneous raids on conspirators' offices in the two countries.
} 
We assume that during the admission of a cartel member to the leniency program, the investigating AA seizes information pertaining to the cartel activities in the adjacent market. According to policy (I-3) the investigating AA shares this information with its partner AA and this leads to a successful prosecution in the other country even if the other AA was not successful in its own investigation. Note that the three information sharing policies could be modeled in a stochastic set-up such that the different spillovers occur with a probability less than one. We found that the deterministic modeling approach includes all interesting effects and is analytically more convenient to derive the main results.

\section{Equilibrium Analysis without Information Sharing}

\subsection{Collusion and Self-Reporting in a Single Market}

As a useful benchmark we first consider cartel formation when firms operate in exactly one market. In the next subsection we analyze global cartel formation. In a single-market setting firms have three different strategic options: (i) collude and self-report if an investigation opens, (ii) collude and not reveal, and (iii) not collude ${ }^{10}$ First, consider the collude and self-report strategy. An investigation opens with probability $\alpha$ each period. Firms apply simultaneously for leniency. By assumption, each firm is equally likely to be the first firm to come forward and receive amnesty. The other firm pays the full antitrust fine. Hence, expected antitrust costs for a firm are $F / 2$ and total profits with this strategy are

$$
V_{R}=\frac{(1-\alpha) \pi / 2-\alpha F / 2}{1-\delta}
$$

Deviations from this equilibrium strategy can occur at two points, at the pricing or the self-reporting stage. Given the rival is applying for leniency in equilibrium, it is always optimal for a firm to self-report. Define $\varphi=F / \pi$ as the fine-profit ratio. The cartel is sustainable at the pricing stage if and only if

$$
V_{R} \geq \pi \quad \text { or } \quad \varphi \leq \frac{2 \delta-1-\alpha}{\alpha} \equiv \varphi_{R}
$$

This holds for sufficiently low fine-profit ratios, a high discount rate and a low probability of a cartel lead. Note that under assumption (A1) the threshold $\varphi_{R}$ is strictly positive.

Next consider the strategy to collude and not to reveal if an investigation begins. The equilibrium profits from this are

$$
V_{N}=\frac{(1-\alpha \beta) \pi / 2-\alpha \beta F}{1-\delta}
$$

${ }^{10}$ The analysis of the single-market case closely follows Motta and Polo (2003). 
Suppose the local AA opens a cartel investigation. A firm prefers not to self-report if its expected profits under the current investigation plus the future cartel profits outweigh full amnesty, i.e.

$$
(1-\beta) \pi / 2-\beta F+\delta V_{N} \geq 0 \quad \text { or } \quad \varphi \leq \frac{1-\beta[1-\delta(1-\alpha)]}{2 \beta[1-\delta(1-\alpha)]} \equiv \varphi_{N} .
$$

Note that for $(1-\beta) /(2 \beta)<\varphi \leq \varphi_{N}$ firms expect negative current period profits from the investigation when they are not self-reporting. However, the potential loss of future collusion prevents them from deviating. At the pricing stage a firm does not undercut its rival if and only if

$$
V_{N} \geq \pi \quad \text { or } \quad \varphi \leq \frac{2 \delta-1-\alpha \beta}{2 \alpha \beta} .
$$

Under assumption (A1) this condition always holds if (2) is satisfied and the binding constraint for the cartel is the incentive not to report ${ }^{11}$ Compare conditions (1) and (2). Since $\varphi_{N}$ is decreasing in $\beta$ while $\varphi_{R}$ is constant, there exists a $\bar{\beta}_{1}$ such that for all $\beta$ lower than this threshold it is harder to sustain collusion with reporting while for higher values it is harder to sustain collusion without reporting. Thus, for $\beta \leq \bar{\beta}_{1}$ and $\varphi_{R} \leq \varphi \leq \varphi_{N}$ firms can only sustain collusion without self-reporting. If $\beta$ is larger than this threshold and $\varphi_{N} \leq \varphi \leq \varphi_{R}$, then firms collude with self-reporting. By contrast, if both (1) and (2) are satisfied, firms collude with the self-reporting strategy that yields the highest expected pay-off. They choose to collude and not reveal if

$$
V_{N} \geq V_{R} \quad \text { or } \quad \varphi \leq \frac{1-\beta}{2 \beta-1} \equiv \varphi^{*} .
$$

Collusion with self-reporting implies a shorter cartel duration but firms expect to pay only half of the stipulated antitrust fine. When firms collude without self-reporting they face the (full) antitrust fine with probability $\beta$. Hence, if $\beta \leq 1 / 2$, then not revealing is always optimal. Otherwise, self-reporting is optimal if the fine-profit ratio and $\beta$ are sufficiently high. Further check that there exists a unique $\bar{\beta}_{2}$, with $\bar{\beta}_{2} \geq \bar{\beta}_{1}$, such that $\varphi^{*} \leq \varphi_{N}$ if and only if $\beta \geq \bar{\beta}_{2}$. This implies that collusion without self-reporting always Pareto dominates for $\beta \leq \bar{\beta}_{1}$ when (1) is the binding constraint. By contrast, collusion with self-reporting Pareto dominates if $\beta$ is sufficiently close to 1 .

Lemma 1 The optimal cartel strategy in a single market is as follows. If $\varphi \leq \min \left\{\varphi_{N}, \varphi^{*}\right\}$, then firms collude and do not self-report. If $\varphi>\min \left\{\varphi_{N}, \varphi^{*}\right\}$ and $\varphi \leq \varphi_{R}$, then firms collude and self-report. Otherwise, a cartel is not sustainable.

This result is illustrated in a $\varphi-\beta$ diagram in Figure 1. If the fine-profit ratio and the prosecution probability are low, firms collude without self-reporting. For high values of $\beta$

${ }^{11}$ This is shown in the proof of Lemma 1. All proofs are relegated to the appendix. 
and intermediate $\varphi$ firms collude and self-report. Note that for $\beta \leq \bar{\beta}_{2}$ and $\varphi \in\left[\varphi_{N}, \varphi^{*}\right]$, firms are in a prisoners' dilemma situation and face a cooperation problem. The most profitable organization of collusion is not to reveal but firms have an unilateral incentive to deviate and self-report. ${ }^{12}$ If additionally $\varphi \leq \varphi_{R}$, then firms can collude with reporting instead. However, for higher fine-profit ratios the cartel is not sustainable.

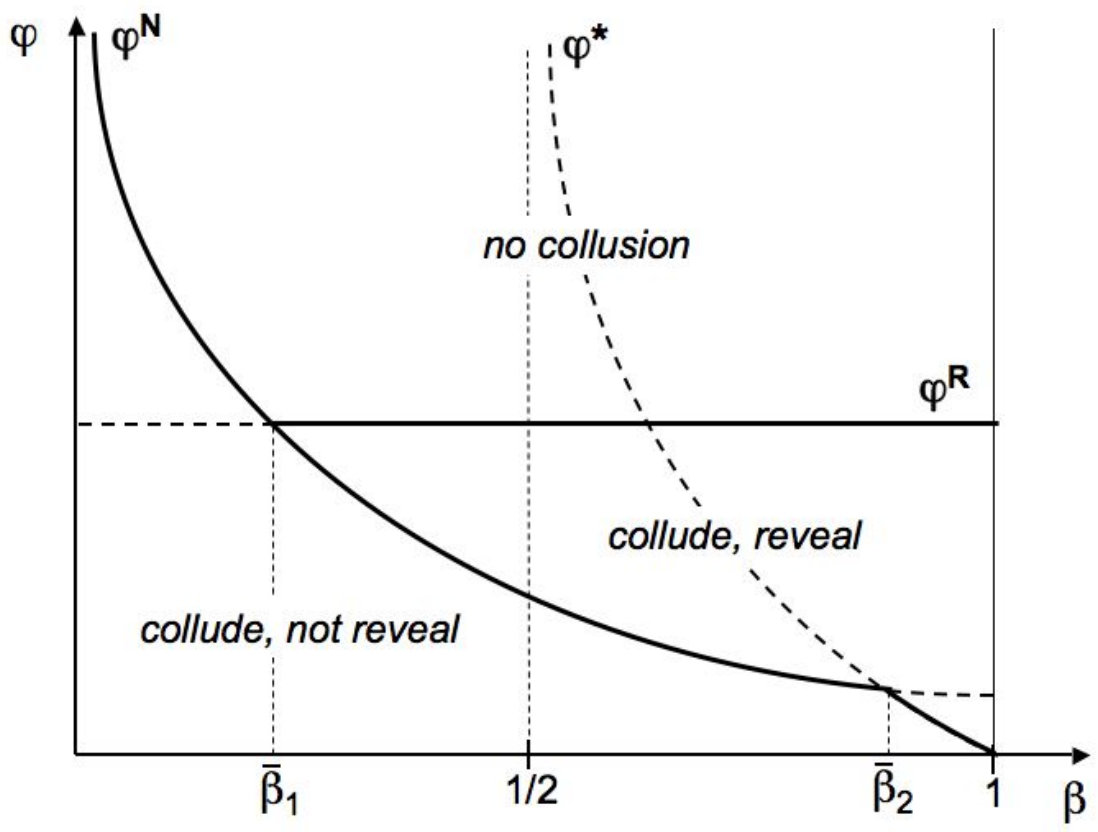

Figure 1: Collusion and self-reporting in a single market.

\subsection{Collusion and Self-Reporting with Multi-Market Contact}

Suppose firms form cartels in both markets and the local antitrust authorities do not cooperate, i.e. they independently follow up on leads and prosecute without information sharing. This implies that, in any period, firms might be under investigation in one country, two countries or not at all. A revelation strategy for a firm specifies in which countries it applies for leniency when one or two investigations open. Denote $I \in\{1,2\}$ as the number of open investigations in a given period 13 To simplify notation, we describe a self-reporting strategy by the number of applications that a firm files. This is sufficient since it will never be optimal for a firm to self-report in a country without investigation while not revealing

\footnotetext{
${ }^{12}$ Note that for $0<\varphi \leq \varphi_{N}$ mixed strategy equilibria exist in which firms randomize between reporting or not. The mixed strategy equilibria is, however, always dominated by the pure strategy equilibrium without self-reporting. For $\varphi>\varphi_{N}$ mixed strategy equilibria fail to exist.

${ }^{13}$ Self-reporting without any open investigation is always strictly dominated and we drop this case for notational convenience.
} 
in a country with an open investigation.14 Thus, denote $r(I) \in\{0,1,2\}$ as the number of self-reports of a firm when $I$ investigations open. A complete description of a firm's self-reporting strategy is given by the pair $(r(1), r(2))$. Further let $V_{i j}$ denote the expected equilibrium profit if both firms collude and use the revelation strategy $(i, j)$. This profit is recursively defined as

$$
(1-\delta) V_{i j}=2 \alpha(1-\alpha) u_{i}+\alpha^{2} v_{j}+(1-\alpha)^{2} \pi
$$

where $u_{i}\left(v_{j}\right)$ is the expected interim value if one (two) investigation(s) open and firms self-report to $i(j) \in\{0,1,2\}$ local authorities. If exactly one cartel investigation opens and firms apply for leniency in $i$ countries, their expected value is given by

$$
u_{i}= \begin{cases}\pi / 2+(1-\beta) \pi / 2-\beta F & \text { if } i=0, \\ \pi / 2-F / 2 & \text { if } i=1, \\ -F & \text { if } i=2 .\end{cases}
$$

If firms do not self-report, there is a probability $\beta$ that they are successfully prosecuted in the country where the investigation opens. In this case, they lose their local cartel profits and pay the antitrust fine $F$. If firms self-report the cartel under investigation, each firm receives amnesty with probability $1 / 2$. Finally, if they self-report in both countries, the expected antitrust fine is $F$ across the two jurisdictions.

If two cartel investigations open and firms self-report to $j$ antitrust authorities, they receive an expected value of

$$
v_{j}= \begin{cases}(1-\beta) \pi-2 \beta F & \text { if } j=0, \\ -F / 2+(1-\beta) \pi / 2-\beta F & \text { if } j=1, \\ -F & \text { if } j=2 .\end{cases}
$$

If firms do not self-report at all, they face in each country prosecution with probability $\beta$, in which case they pay $F$ and lose their cartel profits. If they self-report in exactly one and the same country, they face an expected antitrust liability of $F / 2$ in this jurisdiction and the possibility of prosecution in the other market. Before analyzing optimal cartel formation, compare the values of the self-reporting strategies available to a global cartel.

Lemma 2 The ranking of the values of the self-reporting strategies are as follows.

(i) For any $\varphi$ it holds that $V_{1 j}>V_{2 j}, \forall j \in\{0,1,2\}$.

(ii) If $\varphi \leq \varphi^{*}$, then it holds that

\footnotetext{
${ }^{14}$ We also assume that if firms self-report in exactly one jurisdiction, they are able to coordinate in which country they apply for leniency.
} 


$$
\begin{aligned}
& V_{0 j} \geq V_{1 j}, \forall j \in\{0,1,2\} \text { and } \\
& V_{i 0} \geq V_{i 1} \geq V_{i 2}, \forall i \in\{0,1,2\}
\end{aligned}
$$

If $\varphi>\varphi^{*}$, the two rankings are reversed.

Part (i) states that self-reporting in two countries when one investigation opens is strictly dominated by self-reporting only to the investigating antitrust authority. This follows directly from comparing $u_{1}$ and $u_{2}$. Self-reporting to the non-investigating authority leads to the loss of cartel profits and an expected antitrust fine of $F / 2$ in this market. Part (ii) implies that if self-reporting is Pareto dominated in the single-market case, i.e. if (4) holds, then expected cartel profits are higher, the less cartels under investigation are self-reported. Vice versa, if $\varphi \geq \varphi^{*}$, then expected cartel profits increase in the number of self-reports. This result follows from the independence of antitrust efforts across the two jurisdictions.

Let us turn to the incentive constraints to sustain collusion with these self-reporting strategies. First, consider parameter values such that reporting strategy $(1,2)$ is the Pareto dominant strategy, i.e. assume $\varphi \geq \varphi^{*}$. Reporting all cartels under investigation is always optimal given the rival is reporting. Thus, the cartel is only constrained by price deviations. Due to the independence of prosecution outcomes it holds that expected profits with multimarket contact are twice the profits from the single-market analysis, $V_{12}=2 V_{R}$. It follows that the pricing constraint $V_{12} \geq 2 \pi$ holds if and only if (1) is satisfied. Furthermore, Lemma 2 implies that other reporting strategies yield lower expected profits and are not sustainable since their pricing constraints, $V_{i j} \geq 2 \pi$, are violated if (1) does not hold.

Next consider cases where it is Pareto dominant for firms to collude and not reveal any cartel, i.e. assume $\varphi \leq \varphi^{*}$. Suppose firms follow strategy $(0,0)$ and investigations in both countries open. An individual firm is not applying for leniency in any of the two markets if its current period profits plus future cartel profits exceed the gains from self-reporting the cartel in one or both countries. Since the other firm is not revealing in equilibrium, self-reporting ensures full amnesty for all reported cartels. However, if one or both cartels are revealed, firms trigger eternal reversion to competition in both markets. Hence, if a firm deviates and self-reports one cartel it receives amnesty and the expected profit from the cartel in the other market. If a firm self-reports both cartels, it makes no profit. It follows that self-reporting one cartel is the optimal deviation if the current period profit with the non-reported cartel is positive. The incentive constraint for not self-reporting any cartel is therefore

$$
v_{0}+\delta V_{00} \geq \begin{cases}v_{0} / 2 & \text { if } \varphi \leq(1-\beta) /(2 \beta) \\ 0 & \text { otherwise }\end{cases}
$$


From the independence of investigation outcomes across the two jurisdictions follows that $V_{00}=2 V_{N}$. Compared to (2), firms receive twice the continuation profit if they are not self-reporting. At the same, if a firm deviates to one self-report, then its net current period value is the same as in (2). Thus, if (2) holds, then firms have no incentive to deviate to one self-report. Since $(1-\beta) /(2 \beta)<\varphi_{N}$, the first part of $(00)$ is always satisfied. On the other hand, if a firm optimally deviates to reveal both cartels, firms receive twice the current period profit from the single-market constraint and (2) coincides with the second part of (00). Hence, not self-reporting any cartel when two investigations open is incentive compatible if and only if $\varphi \leq \varphi_{N}$. Suppose an investigation in exactly one country opens. If an individual firm does not apply for leniency its current period profits are $v_{0} / 2$ from the market under investigation plus the cartel profits $\pi / 2$ from the other market. The optimal deviation is to self-report the cartel under investigation which yields amnesty in this market and cartel profits $\pi / 2$ in the other market. Compared to (2), firms receive the same current period net value and twice the continuation value. Thus, such a deviation is never optimal if (2) holds. At the pricing stage, an individual firm has no incentive to deviate if $V_{00}=2 V_{N} \geq 2 \pi$ which is equivalent to condition (3) and, by assumption (A1), always holds for $\varphi \leq \varphi_{N}$. Consequently, if and only if (2) holds, firms can implement their first-best cartel organization in which they never self-report price fixing.

Now consider self-reporting strategies for parameter values such that $\varphi_{N}<\varphi \leq \varphi^{*}$. First check strategies $(i, 0)$ such that firms self-report to $i \in\{1,2\}$ antitrust authorities if one investigation opens and to none if two investigations open. To ensure no self-reporting when two investigations open it has to hold that $v_{0}+\delta V_{i 0} \geq 0$. Since $V_{i 0} \leq V_{00}$ this can never hold if (2) is not satisfied. Next analyze strategy $(0,1)$ where firms report exactly one cartel when two investigations open. If both AAs launch investigations, firms expect in the current period an antitrust cost of $-F / 2$ in the market they self-report and $v_{0} / 2$ in the market under investigation. The best deviation from one-self-report is to reveal both cartels. In this case the deviating firms gets full amnesty in one market but still faces the antitrust cost of $-F / 2$ in the other market. Thus, self-reporting exactly one cartel is sustainable if and only if

$$
(1-\beta) \pi / 2-\beta F-F / 2+\delta V_{01} \geq-F / 2 .
$$

The net current period value is the expected profit from the non-reported cartel. Since $\varphi>\varphi_{N}$, this value is always negative and firms can sustain this constraint if the future cartel profits outweigh the expected current period loss. Suppose one investigation opens. In the current period firms expect $v_{0} / 2$ in the market under investigation and $\pi / 2$ in the other market. Deviating by self-reporting the cartel under investigation gives amnesty plus cartel profits in the other market. Thus, the net current period value and the continuation 
profit are the same as in (01) and not reporting the cartel under investigation is sustainable if and only if condition (01) is satisfied. Denote $\varphi_{01}$ as the threshold value such that for any lower fine-profit ratio this condition holds. Finally, at the pricing stage it is required that

$$
V_{01} \geq 2 \pi
$$

The next lemma compares the self-reporting and pricing constraint.

Lemma 3 Consider cartel formation with self-reporting strategy $(0,1)$. There exists a $\bar{\beta}_{01}<\bar{\beta}_{1}$ such that the following holds. (i) If (2) does not hold, then condition (01) is always harder to sustain than 01-P). (ii) If $\beta \geq \bar{\beta}_{01}$, then there always exist values $\varphi \in\left[\varphi_{N}, \varphi_{01}\right]$ such that (01) holds while (2) is not satisfied.

If a $(0,0)$ equilibrium is not sustainable, then the binding constraint for the $(0,1)$ equilibrium is the condition that ensures that firms' self-reporting incentives are in place. A necessary and sufficient condition for this constraint to be more restrictive than the pricing constraint is that the probability of a cartel lead is sufficiently low in order to satisfy (A1). A lower $\alpha$ relaxes both constraints but its effect on (01) is weaker since this is an interim constraint and an investigation has already started. Point (ii) states that there always exist parameter values such that a $(0,0)$ equilibrium is not sustainable whereas a $(0,1)$ equilibrium can be sustained. This is because the binding constraint in the equilibrium without any self-reporting is the condition that ensures firms are not applying for leniency when two investigations open. In a $(0,1)$ equilibrium this condition is replaced with the weaker constraint to report one cartel. Note that it follows from $\bar{\beta}_{01}<\bar{\beta}_{1}$ that there exist fine-profit ratios $\varphi \geq \max \left\{\varphi_{R}, \varphi_{N}\right\}$ at which firms can sustain a cartel with self-reporting strategy $(0,1)$.

Suppose cartels with self-reporting strategy $(0,1)$ are not sustainable and consider equilibria with $(i, 1), i \in\{1,2\}$. When two investigations open, these strategies yield the same current period net value as in (01). However, since we focus on parameter values such that $V_{01}>V_{11}>V_{21}$, these strategies are not sustainable for $\varphi>\varphi_{01}$. Next consider self-reporting strategies $(i, 2)$ in which firms report both cartels if two investigations open. These strategies are robust with respect to deviations when both jurisdictions open investigations. First, assume firms do not self-report if exactly one investigation opens. In the current period firms expect profits of $v_{0} / 2$ in the market under investigation and $\pi / 2$ from the adjacent market. Deviating by self-reporting the cartel under investigation yields amnesty in this market and cartel profits from the other market. In other words, the current period net value is the same as in (01) but, since $V_{02}<V_{01}$, the continuation profits are strictly smaller. Hence, if a $(0,1)$ equilibrium is not sustainable, then a $(0,2)$ equilibrium is not sustainable either. Finally, consider reporting strategy $(1,2)$. This strategy yields 
lower profits but it satisfies both reporting constraints and is only limited by the deviation incentives at the price stage. As discussed above, this equilibrium can be supported as long as (1) holds. To see that there exist parameter values for $\varphi \leq \varphi^{*}$ such that an equilibrium with $(1,2)$ can be supported whereas a $(0,1)$ equilibrium fails to hold, note that along $\varphi=\varphi^{*}$, we have $V_{01}=V_{12}$ and the pricing constraints of the two strategies coincide. However, the $(0,1)$ equilibrium is constrained by the self-reporting constraint (01) which is more restrictive than the pricing constraint. Hence, there must exist values

$$
\varphi_{01}<\varphi \leq \min \left\{\varphi_{R}, \varphi^{*}\right\}
$$

such that self-reporting strategy $(1,2)$ is sustainable whereas $(0,1)$ is not. The following proposition and Figure 2 below summarize our findings.

Proposition 1 Consider cartel formation and self-reporting with multi-market contact.

(i) If $\varphi \leq \min \left\{\varphi_{N}, \varphi^{*}\right\}$, then firms collude and use self-reporting strategy $(0,0)$.

(ii) If $\varphi_{N}<\varphi \leq \min \left\{\varphi_{01}, \varphi^{*}\right\}$, then firms collude and use self-reporting strategy $(0,1)$.

(iii) If $\varphi_{01}<\varphi \leq \min \left\{\varphi_{R}, \varphi^{*}\right\}$, then firms collude and use self-reporting strategy $(1,2)$.

(v) Otherwise, a cartel is not sustainable.

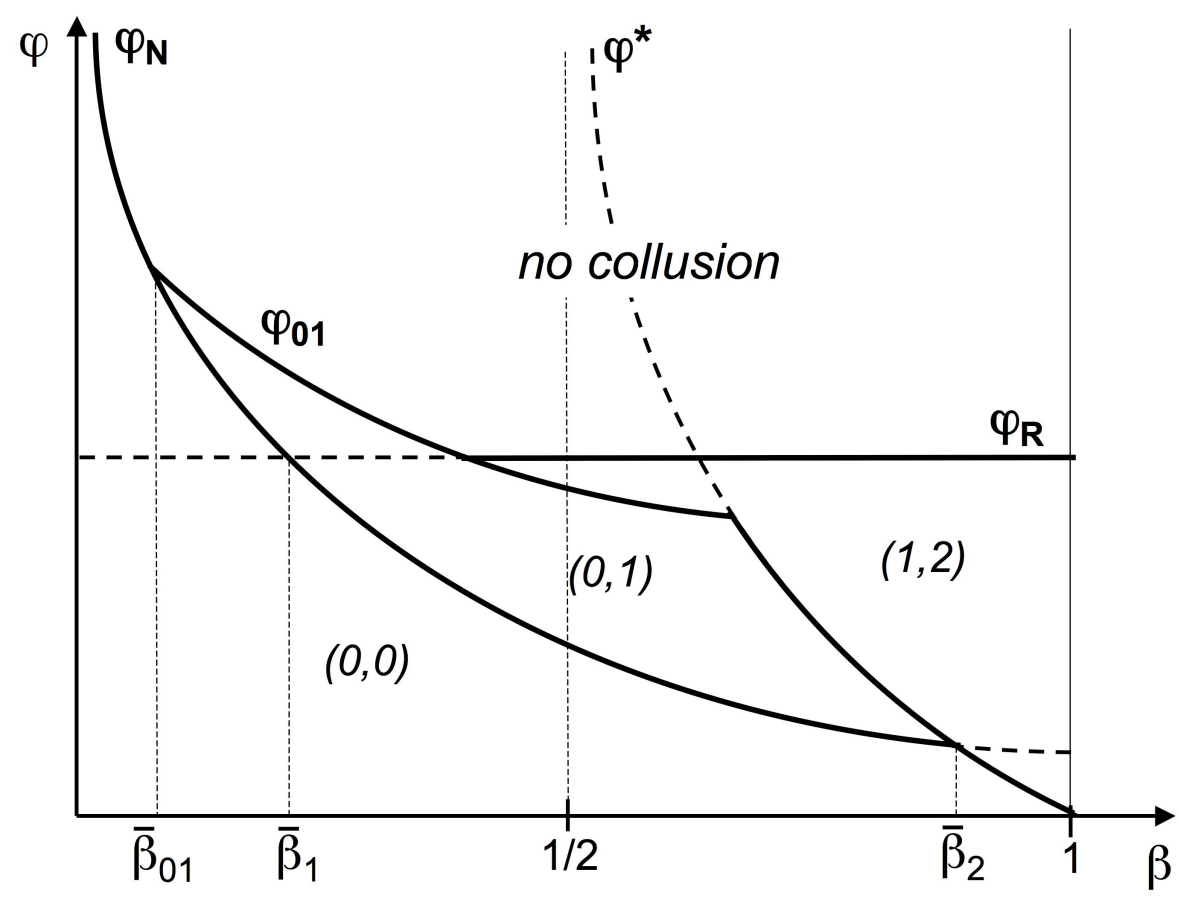

Figure 2: Self-reporting equilibria without antitrust cooperation.

These results identify two effects of multi-market contact on self-reporting incentives and cartel formation. Compared to the single-market analysis, firms can sustain collusion with 
less self-reporting and form a cartel in situations where collusion is not feasible when firms are local operators. Multi-market contact allows firms to pool their incentive constraints across the two markets. As discussed above, this is not effective when firms are not selfreporting any cartel. The current period net value and the continuation cartel profit are exactly twice as much as in the single-market case. However, for $\varphi_{N} \leq \varphi \leq \varphi^{*}$, local firms face a prisoner dilemma situation and collusion with self-reporting is the only sustainable cartel organization although they would be better off not revealing. By contrast, global firms are able to sustain the partial self-reporting equilibrium $(0,1)$. To see this compare (2) and (01). The single-market constraint ensures that firms are not revealing their local cartel under investigation. The multi-market constraint requires firms to self-report exactly one cartel when two investigations start. The self-reported cartel in (01) decreases current period equilibrium profits and deviation profits by $F / 2$ and the net current value is identical in both constraints. Hence, (01) is easier to sustain since the continuation profit $V_{01}$ from two markets is larger than the continuation value from one market $V_{N}$. Put differently, the multi-market cartel is able to transfer slack collusive rent from the market where they self-report to the adjacent market and curb the incentives to reveal the second cartel. Thus, for parameter values

$$
\varphi_{N}<\varphi \leq \min \left\{\varphi_{R}, \varphi_{01}, \varphi^{*}\right\}
$$

firms collude and self-report in the single-market analysis whereas with multi-market contact, firms do not report when one investigation starts and they report exactly one cartel when two investigations open. Since this strategy yields higher expected profits than selfreporting all cartels under investigation, it is clear that there exist parameter values

$$
\varphi_{N}<\varphi \leq \min \left\{\varphi_{R}, \varphi_{01}, \varphi^{*}\right\}
$$

such that firms can support collusion if only if they have multi-market contact. This result is a marked difference to Bernheim \& Whinston (1990) because it holds in our setting for ex ante identical markets. In equilibrium firms use a partial self-reporting strategy which creates interim asymmetry between the market in which the cartel is reported and the market where the cartel is investigated. This allows interim incentive pooling and prevents self-reporting. As a consequence, multi-market firms make higher global profits and form more cartels compared to local firms.

Corollary 1 Multi-market contact allows firms to support collusion with less self-reporting and form cartels when collusion is not sustainable in a single market. 


\section{Equilibrium Analysis with Information Sharing}

Suppose the antitrust authorities enter an agreement by which they exchange information according to policies (I-1) and (I-2). Each local AA reports a cartel lead to its partner AA which allows a successful prosecution of the cartel in the adjacent market with probability $\beta$. Ex ante at least one AA receives a cartel lead with probability $A \equiv \alpha(2-\alpha)$ and investigations in both jurisdictions start. Furthermore, AAs share the information they receive during an investigation. If a cartel is successfully prosecuted in one jurisdiction but not in the other one, then the successful AA is able to provide information to prosecute the cartel in the second country. This implies that after the start of investigations in both countries, firms are successfully prosecuted in both jurisdictions with probability $B \equiv \beta(2-\beta)$. With the remaining probability, firms avoid antitrust enforcement in both markets. To simplify the exposition in this section we focus on situations where the discount factor is high and the probability of a cartel lead small enough in order to satisfy

$$
\delta \geq \frac{1+A}{2(1-A)}
$$

This constraint is harder to satisfy than (A1) if and only if $\alpha$ is sufficiently large.

A firm's expected equilibrium profit with information sharing among AA is recursively defined as

$$
(1-\delta) V_{j}^{\prime}=\alpha(2-\alpha) v_{j}^{\prime}+(1-\alpha)^{2} \pi
$$

where $v_{j}^{\prime}$ is the interim profit when investigations in both countries open and firms selfreport to $j$ antitrust authorities. This interim profit is given by

$$
v_{j}^{\prime}= \begin{cases}(1-B) \pi-B 2 F & \text { if } j=0, \\ -F / 2+(1-\beta) \pi / 2-\beta F & \text { if } j=1, \\ -F & \text { if } j=2 .\end{cases}
$$

If firms do not self-report, they end up being convicted in both markets or not at all. The former occurs if at least one AA is successful in desisting the cartel and firms pay the stipulated antitrust fine to both authorities. Alternatively, if firms self-report in only one country, they receive the same expected profits as in the previous section since AAs are not sharing leniency program information. They get amnesty with probability $1 / 2$ in the country they self-report but they still face the possibility of being prosecuted in the other country.

Compare the value of the self-reporting strategies available to the global cartel when the AAs cooperate. Not self-reporting dominates self-reporting exactly one cartel if and only if

$$
v_{0}^{\prime} \geq v_{1}^{\prime} \quad \text { or } \quad \varphi \leq \frac{(1-\beta)(1 / 2-\beta)}{2(1-\beta) \beta+\beta-1 / 2} \equiv \varphi_{01}^{*}
$$


i.e. if the fine-profit ratio and the prosecution probability are sufficiently small. The threshold value strictly decreases in the prosecution probability, goes to infinity for $\beta$ towards $(3-\sqrt{5}) / 4 \simeq 0.191$ and is positive if and only if $\beta \leq 1 / 2$. Hence, when $\beta$ is smaller than 0.191, then no self-report dominates independent of the antitrust fine. By contrast, when $\beta>1 / 2$ self-reporting one cartel is always superior. This and the following thresholds are depicted in a $\varphi-\beta$ diagram in FigurE 3 . Next check that reporting one cartel dominates reporting both cartels if and only if (4) holds, i.e. for $\varphi \leq \varphi_{12}^{*} \equiv \varphi^{*}$. Not self-reporting dominates self-reporting both cartels if and only if

$$
v_{0}^{\prime} \geq v_{2}^{\prime} \quad \text { or } \quad \varphi \leq \frac{1-B}{2 B-1} \equiv \varphi_{02}^{*}
$$

The threshold is decreasing in the prosecution probability, goes to infinity for $\beta$ towards $1-1 / \sqrt{2} \simeq 0.293$ and is positive for all $\beta$. It is easy to check that

$$
\varphi_{01}^{*}<\varphi_{02}^{*}<\varphi_{12}^{*}
$$

and the next lemma follows immediately.

Lemma 4 The profit ranking of the cartel's self-reporting strategies is as follows:

(i) If $\varphi \leq \varphi_{01}^{*}$, then not self-reporting dominates one self-report which dominates two selfreports, $V_{0}^{\prime} \geq V_{1}^{\prime}>V_{2}^{\prime}$.

(ii) If $\varphi_{01}^{*} \leq \varphi<\varphi_{02}^{*}$, then one self-report dominates no self-report which dominates two self-reports, $V_{1}^{\prime} \geq V_{0}^{\prime}>V_{2}^{\prime}$.

(iii) If $\varphi_{02}^{*} \leq \varphi<\varphi_{12}^{*}$, then one self-report dominates two self-reports which dominates one self-report, $V_{1}^{\prime} \geq V_{2}^{\prime}>V_{0}^{\prime}$.

(iv) Otherwise, self-reporting both cartels dominates one self-report which dominates no self-report, $V_{2}^{\prime} \geq V_{1}^{\prime}>V_{0}^{\prime}$.

Let us analyze the conditions under which these strategies are sustainable. First consider the equilibrium in which cartel members self-report all cartels as soon as investigations start. Given the rival firm self-reports both cartels in equilibrium, each firm is best off self-reporting, too. Thus, only the pricing constraint has to be considered. A cartel with full self-reporting is sustainable if and only if

$$
V_{2}^{\prime} \geq 2 \pi \quad \text { or } \quad \varphi \leq \frac{2 \delta-1-A}{A} \equiv \varphi_{2}
$$

Next suppose firms coordinate to self-report in one jurisdiction only. At the pricing stage there is no unilateral incentive to deviate if

$$
V_{1}^{\prime} \geq 2 \pi \quad \text { or } \quad \varphi \leq \frac{2 \delta-1-A(1+\beta) / 2}{A(\beta+1 / 2)} \equiv \varphi_{1 P} .
$$


Given the other cartel member self-reports in exactly one market, a firm prefers to selfreport in exactly the same market if current period gains with two open investigations plus the cartels continuation value outweighs self-reporting both cartels. In this case, the deviating firm expects half of the antitrust penalty from the market in which both firms self-report and antitrust amnesty in the other market. The condition is

$$
v_{1}^{\prime}+\delta V_{1}^{\prime} \geq-F / 2 \quad \text { or } \quad \varphi \leq \frac{(1-\delta)(1-\beta) / 2+\delta-\delta A(1+\beta) / 2}{\delta A(\beta+1 / 2)+(1-\delta) \beta} \equiv \varphi_{1 R} .
$$

Either of the two incentive constraints of this equilibrium can be more restrictive. We show in the appendix to the next proposition that if $\alpha$ sufficiently small and $\delta$ sufficiently large, then there exists a threshold value on $\beta$ such that for lower $\beta$ the pricing constraint is more restrictive where as for larger $\beta$ the self-reporting constraint is more restrictive. It is thus useful to define the locus $\varphi_{1} \equiv \min \left\{\varphi_{1 R}, \varphi_{1 P}\right\}$ below which this equilibrium is sustainable. Lastly, suppose firms collude and do not self-report any cartel. A firm does not deviate at the pricing stage if

$$
V_{0}^{\prime} \geq 2 \pi \text { or } \varphi \leq \frac{2 \delta-1-A B}{2 A B} .
$$

Given its rival is not revealing, a firm prefers not to reveal if the current period profits after the start of investigations plus the continuation value outweighs amnesty in both jurisdictions,

$$
v_{0}^{\prime}+\delta V_{0}^{\prime} \geq 0 \quad \text { or } \quad \varphi \leq \frac{1-B[1-\delta(1-A)]}{2 B[1-\delta(1-A)]} \equiv \varphi_{0} .
$$

We show in the appendix that if and only if $A 2$ holds, then the self-reporting constraint is more restrictive for any value of $\beta$.

It remains to check under which conditions the three self-reporting cartel strategies are sustainable and optimal. Consider $\varphi>\varphi_{12}^{*}$ such that self-reporting all cartels is optimal. This equilibrium is sustainable if additionally (C-2) holds. If this pricing constraint is not satisfied, then the pricing constraints of the two other self-reporting strategies must be violated and no cartel will form. Suppose $\varphi$ is intermediate, $\varphi_{02}^{*} \leq \varphi<\varphi_{12}^{*}$, such that reporting exactly one cartel is optimal. If $\varphi>\varphi_{1}$ and self-reporting one cartel is not sustainable, then there might exist parameter values such that a cartel with full selfreporting can still form. The reason for this is that along $\varphi=\varphi_{12}^{*}$ we have $V_{1}^{\prime}=V_{2}^{\prime}$ and the pricing constraints of the two strategies coincide. However, if $\alpha$ is sufficiently small and $\delta$ sufficiently high, then the incentive constraint to self-report exactly one cartel is stricter than the pricing constraint. Further note that an equilibrium without self-reporting cannot be sustained for $\varphi>\varphi_{1}$ because if $V_{1}^{\prime}>V_{0}^{\prime}$, then the pricing and the self-reporting constraint are harder to sustain compared to the equilibrium with one self-report ${ }^{15}$ Finally,

\footnotetext{
${ }^{15}$ Upon inspection the LHS of $\mathrm{C}-1$ is larger than LHS of $\mathrm{C}-0$ and the RHS of $\mathrm{C}-1$ is smaller than LHS of $(\mathrm{C}-0)$.
} 
consider $\varphi \leq \varphi_{01}^{*}$ such that the optimal cartel organization implies no self-reporting. Along $\varphi=\varphi_{01}^{*}$ it holds that $V_{1}^{\prime}=V_{0}^{\prime}$ and both the pricing and the self-reporting constraints with one self-report self-report one cartel are easier to satisfy than their counterparts when firms are not self-reporting. At the same time verify that for $\beta=0$ condition $\mathrm{C}-0$ is easier to satisfy than both $\mathrm{C}-1 \mathrm{p}$ ) and $\mathrm{C}-1$. Hence there exists a unique value for $\beta$ such that for larger $\beta$ an equilibrium with one self-report can be sustained while a cartel without self-reporting is unable to form ${ }^{16}$ We thus get the following.

Proposition 2 Consider cartel formation and self-reporting when AAs share information. (i) If $\varphi \leq \min \left\{\varphi_{0}, \varphi_{01}^{*}\right\}$, then firms collude and do not self-report.

(ii) If $\min \left\{\varphi_{0}, \varphi_{01}^{*}\right\}<\varphi \leq \min \left\{\varphi_{1}, \varphi_{12}^{*}\right\}$, then firms collude and self-report one cartel.

(iii) If $\min \left\{\varphi_{1}, \varphi_{12}^{*}\right\}<\varphi \leq \varphi_{2}$, then firms collude and self-report in both jurisdictions.

(iv) Otherwise, there is no collusion.

FIGURE 3 summarizes these results. If the fine-profit ratio and the prosecution probability are sufficiently small, then firms sustain their global cartel without any self-reporting. By contrast, if $\varphi<\varphi_{2}$ and $\beta$ sufficiently large, firms collude but self-report all cartels as soon as investigations begin. For low fine-profit ratio and intermediate probabilities of a successful prosecution, firms use a partial self-reporting strategy. When investigations in both jurisdictions start, they self-report to exactly one AA. The confidentiality agreement towards leniency applicants ensures that the AA is not sharing any disclosed information with its partner AA. Nevertheless, firms face the risk of being prosecuted during the course of the investigation in the adjacent market. For example, in the Ductile Pipe cartel case, the US and Canadian antitrust authorities launched parallel investigations of several US and Canada based companies. In September 1995, the Canadian authorities obtained a guilty plea from one of the cartel members, Canada Pipe Company, resulting in a reduced antitrust fine. At the same time, the US authorities continued their investigation but, ultimately, concluded that they did not have sufficient evidence to prosecute ${ }^{17}$

What is the effect of information sharing among AAs on self-reporting and cartel formation? Sharing cartel leads according to policy (I-1) implies that investigations start simultaneously across the jurisdictions. Ex post information sharing under policy (I-2) means that when investigations start, firms are more likely to be successfully prosecuted. Both policies thus reduce the ex ante value of cartels. It follows immediately from comparing (2) and (C-0) that cartels without self-reporting are harder to sustain when AAs share information. Moreover, since (1) is more restrictive than (C-2) we have that cartels with full self-reporting are less stable under $(I-1)$ and (I-2).

\footnotetext{
${ }^{16}$ This follows immediately from the fact that the threshold values $\varphi_{1 R}, \varphi_{1 P}$ and $\varphi_{2}$ are decreasing and convex in $\beta$. See the proof to Proposition 2 in the appendix.

${ }^{17}$ See chapter 4 page 182 of the ICPAC report.
} 


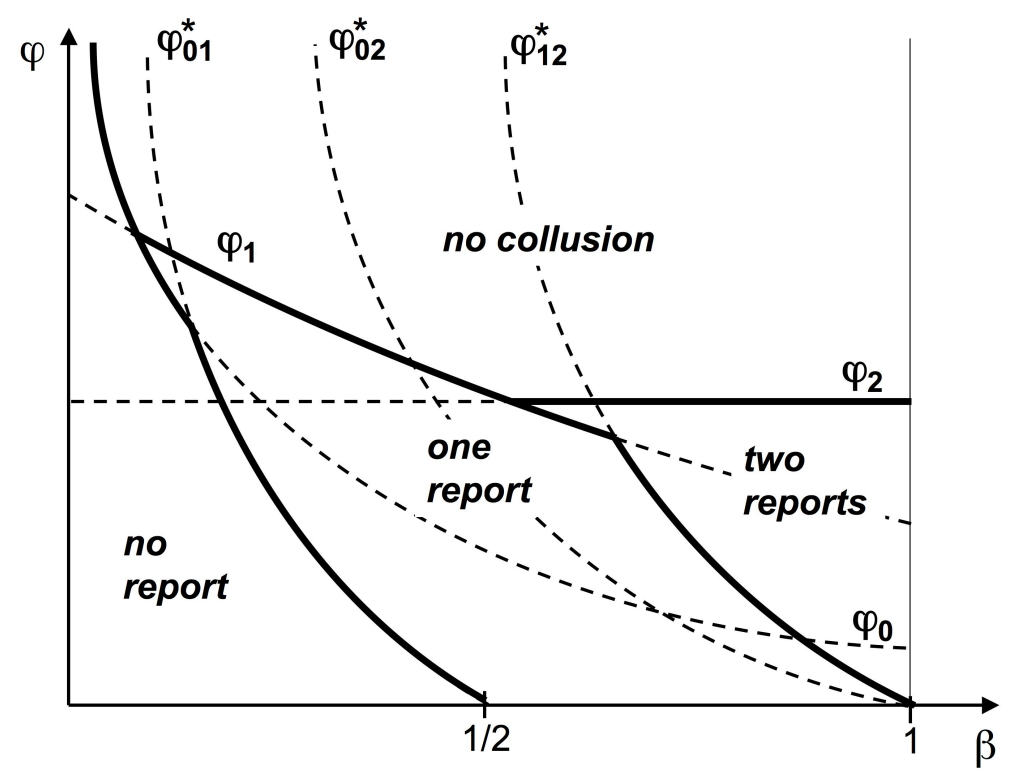

Figure 3: Self-reporting equilibria with information sharing.

Finally, compare the conditions to sustain a $(0,1)$ equilibrium without information sharing and a cartel with one self-report under information sharing. For the former equilibrium, firms should have an incentive to self-report one rather than two cartels when both countries open their investigation, i.e. condition (01) has to hold. For the latter, the pricing constraint (C-1p and the self-reporting condition (C-1) need to be jointly satisfied. Since $v_{1}=v_{1}^{\prime}$, the current period net values in the two self-reporting constraints are the same. However, the expected continuation value without AA cooperation is higher,

$$
V_{01}-V_{1}^{\prime}=\frac{2 \alpha(1-\alpha)}{1-\delta}(\pi / 2-F / 2)>0
$$

Without information sharing, there is a probability of $2 \alpha(1-\alpha)$ with which one cartel is investigated and not reported whereas the other market earns cartel profits. In the same event with AA cooperation, one market is investigated without self-report whereas the other cartel is self-reported. Hence, a cartel with one self-report and information sharing is harder to sustain than a $(0,1)$ cartel without cooperation among the AAs. From this also follows that there is (weakly) more self-reporting with information sharing and the overall effect of information sharing policies $(I-1)$ and (I-2) is positive.

Corollary 2 Information sharing among AAs with policies (I-1) and (I-2) increases selfreporting from firms and deters ex ante cartel formation. 


\section{Equilibrium Analysis with Extensive Information Sharing}

Suppose that antitrust authorities enter an information sharing agreement by which they are not only sharing information according to (I-1) and (I-2) but also information they gather from leniency applicants. Or, put differently, suppose AAs agree not to offer confidentiality agreements to leniency applicants and share all cartel information. What is the effect of such extensive information sharing on cartel formation and self-reporting? The difference to the previous analysis is that when two cartel investigations open and firms self-report to exactly one antitrust authority, information spills over and firms are also prosecuted in the adjacent market. Hence the interim profit when two investigations open and firms report exactly one cartel is $v_{1}^{\prime \prime} \equiv-3 F / 2$. Define a firm's expected cartel value with one self-report, $V_{1}^{\prime \prime}$, as

$$
(1-\delta) V_{1}^{\prime \prime}=A v_{1}^{\prime \prime}+(1-A) \pi
$$

It is clear that a cartel with one self-report can be supported if it jointly satisfies the pricing and self-reporting constraints corresponding to $(\mathrm{C}-1 \mathrm{p})$ and $(\mathrm{C}-1)$. However, if follows from $v_{1}^{\prime \prime}<v_{2}^{\prime}$ that self-reporting both cartels always yields higher expected profits. Moreover, the pricing constraint under extensive information sharing is always more restrictive. In other words, if self-reporting both cartels is not sustainable, then self-reporting one cartel is not sustainable either. Hence, it remains to compare self-reporting both cartels with not selfreporting at all. For $\varphi \leq \varphi_{0}$ and $\varphi \leq \varphi_{2}$ both cartel organizations are sustainable. Firms prefer no self-report rather than reveal both cartels if additionally $\varphi \leq \varphi_{02}^{*}$ is satisfied. Furthermore, if $\beta$ is small, then $\varphi_{2}>\varphi_{0}$ and there exist parameter values such that no self-reporting is the only sustainable equilibrium. By contrast, when $\beta$ is sufficiently large and $\varphi_{0}<\varphi \leq \varphi_{2}$, then self-reporting both cartels is the only viable form of collusion. Finally, when the fine-profit ratio is sufficiently high, then collusion is not sustainable and we can conclude as follows.

Proposition 3 Consider cartel formation and self-reporting with extensive information sharing between the AAs.

(i) If $\varphi \leq \min \left\{\varphi_{0}, \varphi_{02}^{*}\right\}$, then firms collude and do not self-report.

(ii) If $\min \left\{\varphi_{0}, \varphi_{02}^{*}\right\}<\varphi \leq \varphi_{2}$, then firms collude and self-report in both jurisdictions.

(iii) Otherwise, there is no collusion.

We are now in a position to evaluate the additional effect of AAs sharing information obtained through leniency applications by comparing Propositions 2 and 3. 


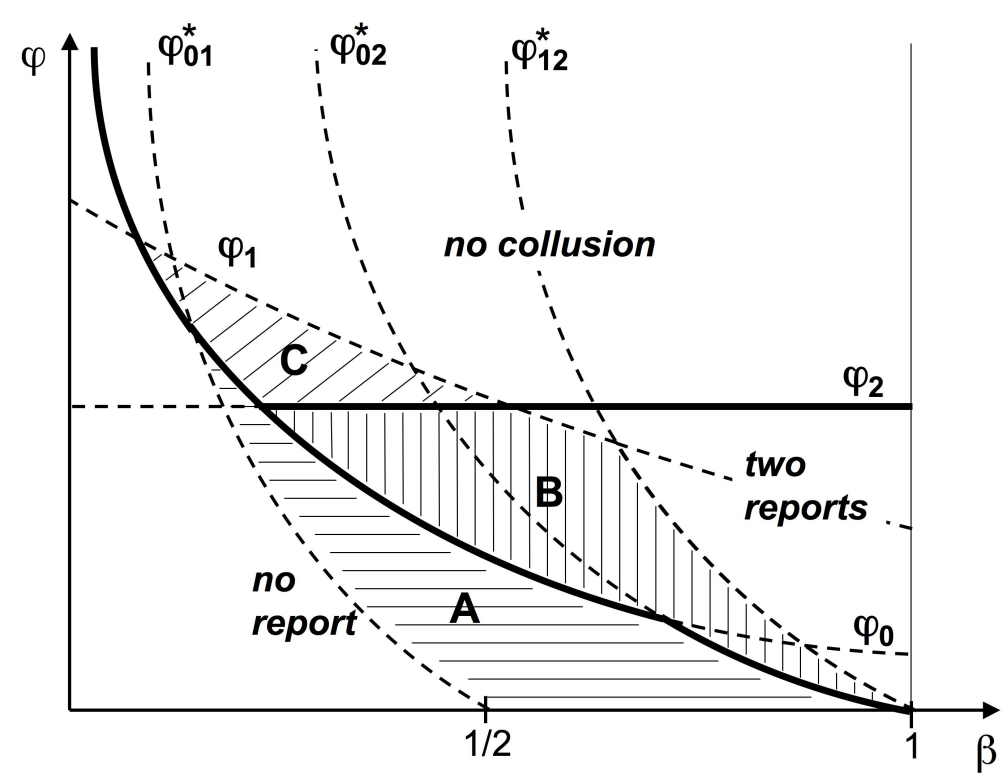

Figure 4: Self-reporting equilibria with extensive information sharing.

As discussed, sharing information pertaining to leniency program applications reduces the value of reporting in only one jurisdiction. At the same time the value of not reporting or reporting both cartels is not affected by information sharing policy (I-3). Consider parameter region A in FigURE 4 which holds for values such that

$$
\varphi_{01}^{*} \leq \varphi \leq \min \left\{\varphi_{0}, \varphi_{02}^{*}\right\}
$$

For these values, firms optimally self-report one cartel when AAs share information according to (I-1) and (I-2). However, if AAs additionally share leniency program information, firms do not report any cartel as long as this equilibrium can be supported $\left(\varphi \leq \varphi_{0}\right)$ and as long as this strategy dominates reporting both cartels $\left(\varphi \leq \varphi_{02}^{*}\right)$. Hence, information sharing policy (I-3) reduces the number of leniency applications from one to zero. This is precisely the argument suggested in the speech by Hammond (2003). Extensive information sharing among AA might reduce the incentives to self-report and mitigate the effectiveness of leniency programs. This outcome is more likely to occur if the fine-profit ratio is low and the investigation success probability is low to medium. In parameter region B of FIGURE 4 sharing leniency program information has the exact opposite effect. Under $(I-1)$ and (I-2) firms can support equilibria with one or two self-reports but, as $\varphi \leq \varphi_{12}^{*}$, firms prefer to self-report only one cartel. If AAs additionally use policy ( $I$-3), then the number of leniency application increases from one to two. This holds for intermediate values of the fine-profit ratio and medium to high values of the investigation success probability. More specifically, (I-3) increases self-reporting if

$$
\min \left\{\varphi_{0}, \varphi_{02}^{*}\right\} \leq \varphi \leq \min \left\{\varphi_{1}, \varphi_{2}, \varphi_{12}^{*}\right\}
$$


Finally, in region $\mathrm{C}$ the fine-profit ratio is sufficiently high such that neither cartels without self-reporting nor with full self-reporting are sustainable. However, if AAs share information according to (I-1) and (I-2), firms can sustain a cartel with one self-report. Hence, if and only if

$$
\min \left\{\varphi_{0}, \varphi_{2}\right\} \leq \varphi \leq \varphi_{1}
$$

extensive information sharing has a ex ante cartel deterrence effect.

Corollary 3 The additional effect of information sharing policy (I-3) is as follows.

(i) In parameter region A extensive information sharing reduces self-reporting.

(ii) In parameter region $B$ extensive information sharing increases self-reporting.

(iii) In parameter region $C$ extensive information deters cartel formation.

\section{Conclusions}

Over the past decade, antitrust authorities around the world have singled out leniency programs and international antitrust cooperation as their most potent instruments in their fight against global cartels. This paper explores the relationship between cartel formation, information sharing between antitrust authorities and the effectiveness of leniency programs. We consider three different scenarios as function of how much and which type of information antitrust authorities exchange.

In our benchmark model we show that when local authorities are not sharing any information, multinational firms self-report less often and find it easier to sustain a cartel compared to strictly local firms. The reason is that partial self-reporting strategies allow firms to introduce interim asymmetries among otherwise identical markets. This enables firms to pool cartel stability constraints and transfer slack collusive rent to the market where firms decide not to self-report. When antitrust authorities cooperate by sharing cartel leads and case information but keep information obtained through leniency applications confidential, two benefits arise. In each local market cartels face a higher probability of detection and a higher probability of prosecution. This unambiguously increases selfreporting and reduces cartel formation. In the absence of confidentiality agreements with local leniency applicants, extensive information sharing implies that firms strictly prefer equilibria in which they self-report all cartels rather than just applying in one jurisdiction. However, not reporting any cartel dominates both equilibria if the success probability of the antitrust authority's investigation is relatively small and the fine-profit ratio is low. By contrast, if the probability of successfully prosecuting the cartel is sufficiently high, then sharing information from leniency programs actually increases self-reporting and deters cartel formation. Our analysis therefore warrants the cautious approach of competition 
authorities with respect to sharing information from self-reporting companies in the implementation of leniency programs.

\section{Appendix}

\section{Proof of Lemma 1}

The proof is sketched in the main text. It remains to compare (2) and (3) and show that

$$
\varphi_{N}-\frac{2 \delta-1-\alpha \beta}{2 \alpha \beta}=\frac{(1-\delta)[\alpha(2 \delta+1)-2 \delta+1]}{2 \alpha \beta(1-\delta(1-\alpha))} \leq 0,
$$

if and only if $\delta \geq(2+2 \alpha) /[4(1-\alpha)]$ which always holds under (A1). Further we need to show that $\bar{\beta}_{2} \geq \bar{\beta}_{1}$. Check that $\varphi_{R} \geq \varphi_{N}$ if and only if

$$
\beta \geq \frac{1}{\left(2 \varphi_{R}+1\right)(1-\delta(1-\alpha))} \equiv \bar{\beta}_{1} .
$$

Check that $\varphi^{*} \leq \varphi^{N}$ if and only if

$$
\beta \geq \frac{1}{1+\delta(1-\alpha)} \equiv \bar{\beta}_{2} .
$$

Finally, compare the two thresholds and compute

$$
\bar{\beta}_{2}-\bar{\beta}_{1}=\frac{2(1-\delta)[2 \delta-1-\alpha(2 \delta+1)]}{\alpha\left(2 \varphi_{R}+1\right)(1-\delta(1-\alpha))(1+\delta(1-\alpha))}
$$

which is positive if A1 holds. QED.

\section{Proof of Lemma 3}

Compute the threshold value from (01) as

$$
\varphi_{01} \equiv \frac{1+\delta-\delta \alpha^{2}-\beta \Delta}{\delta \alpha^{2}+2 \beta \Delta}
$$

where $\Delta \equiv 1-\delta(1-\alpha)^{2}$. Condition $01-\mathrm{P}$ holds if and only if $\varphi \leq \varphi_{01}^{p}$ where

$$
\varphi_{01}^{p} \equiv \frac{(2-\alpha)(1-\beta)+2 \varphi^{R}}{2 \beta(2-\alpha)+\alpha} .
$$

First check that $\varphi_{01} \leq \varphi_{01}^{p}$, i.e. 01 is more restrictive than $01-\mathrm{P}$, if and only if

$$
\beta \geq \frac{\alpha^{2}(4 \delta+1)}{\alpha^{2}+8 \delta(1-\alpha)^{2}-4(1+\alpha)} \equiv \bar{\beta}_{01}^{p} .
$$

Next check that $\varphi_{01} \geq \varphi_{N}$, i.e. there exist $\varphi$ such that (01) is satisfied while (2) is not, if and only if

$$
\beta \geq \frac{\alpha^{2}}{2(1-\delta)-\alpha(2-\alpha)[1-\delta(1-\alpha)]} \equiv \bar{\beta}_{01}
$$


Hence, for any $\varphi \geq \varphi_{N}, 01$ is more restrictive than $01-\mathrm{P}$ if and only if $\bar{\beta}_{01}^{p} \leq \bar{\beta}_{01}$. Denote $\omega$ as the product of the denominators of $\bar{\beta}_{01}^{p}$ and $\bar{\beta}_{01}$ and check that

$$
\bar{\beta}_{01}-\bar{\beta}_{01}^{p}=\frac{\alpha^{2}}{\omega}\left[2+\delta\left(2-\alpha^{2}\right)\right][4(1-\alpha) \delta-3-\alpha] \geq 0
$$

holds if and only (A1) holds. Finally, verify that for any $\delta$ it holds that

$$
\bar{\beta}_{1}-\bar{\beta}_{01}=\frac{2(1-\delta)\left[1+\alpha^{2}-2 \alpha(1-\alpha) \delta\right]}{\alpha\left(2 \varphi_{R}+1\right)(1-\delta(1-\alpha))(1+\delta(1-\alpha))}>0
$$

and the lemma holds. QED.

\section{Proof of Proposition 2}

First check that $\varphi_{1 P} \geq \varphi_{1 R}$ if and only if

$$
\beta \geq \frac{A(1+4 \delta)}{8(1-A) \delta-4-3 A} \equiv \beta^{\prime}
$$

Note that $\beta^{\prime}<1$ if $\delta \geq(1+A) /(2-3 A)$ which always holds under A2 . Hence, either condition can be more restrictive. To show that there exist parameter values for $\varphi \in\left[\varphi_{01}^{*}, \varphi_{12}^{*}\right]$ such that self-reporting both cartels can be sustainable while self-reporting one cartel is not, verify that $\varphi_{2} \leq \varphi_{12}^{*}$ if and only if

$$
\beta \leq \frac{2 \delta-1}{2(2 \delta-1)-A} \equiv \beta^{\prime \prime}
$$

Then compute

$$
\beta^{\prime \prime}-\beta^{\prime}=\frac{[4+A-8 \delta][2(1-2 A) \delta-1-A]}{[8(1-A) \delta-4-3 A][2(2 \delta-1)-A]} .
$$

Check that the first factor in the numerator is positive as long as the denominator of $\beta^{\prime \prime}$ is positive. Thus, the difference is positive if and only if $\delta \geq(1+A) /(2-4 A)$ or $\delta$ sufficiently high and $\alpha$ sufficiently low. If $\beta^{\prime \prime}>\beta^{\prime}$, then we argue as follows. From $\varphi_{1 P}\left(\beta^{\prime \prime}\right)=\varphi_{2}\left(\beta^{\prime \prime}\right)$ and the fact that all $\varphi$-thresholds decrease in $\beta$ follows that there exist values that simultaneously satisfy $\varphi \leq \varphi_{12}^{*}$, $\varphi>\varphi_{1 R}$ and $\varphi \leq \varphi_{2}$.

To show that $(\mathrm{C}-0)$ is harder to satisfy than $(\mathrm{C}-0 \mathrm{p})$ check that $\varphi_{0} \leq(2 \delta-1-A B) /(2 A B)$ if and only if

$$
\frac{(1-\delta)[1+A-2(1-A) \delta]}{2 A B[1-\delta(1-A)]} \leq 0
$$

which holds if and only if (A2) in the text is satisfied.

Show that there exist parameter values for $\varphi \leq \varphi_{01}^{*}$ such that self-reporting one cartel can be sustainable while self-reporting both is not. To complete the argument in the text note that $\varphi_{1 P}$, $\varphi_{1 R}$ and $\varphi_{0}$ are decreasing in $\beta$. Further check all three thresholds are convex since

$$
\frac{\partial^{2} \varphi_{1 R}}{(\partial \beta)^{2}}=\frac{[2+\delta(2-A)][1-\delta(1-A)]^{2}}{A(1+2 \beta)^{3}}[\delta A(\beta+1 / 2)+(1-\delta) \beta]^{3}>0
$$


and

$$
\frac{\partial^{2} \varphi_{0}}{(\partial \beta)^{2}}=\frac{4-3 B}{(2-\beta)^{3} \beta^{3}[1-\delta(1-A)]}>0
$$

and

$$
\frac{\partial^{2} \varphi_{1 P}}{(\partial \beta)^{2}}=\frac{4(8 \delta-4-A)}{A(1+2 \beta)^{3}}
$$

which is positive if A2 holds. Finally, for point (i) note that $\varphi_{01}^{*}$ is decreasing and convex in $\beta$, goes to infinity for $\beta$ to 0.191 and takes value 0 at $\beta=1 / 2$. Further, $\varphi_{0}$ is decreasing and convex in $\beta$, goes to infinity for $\beta$ to 0 and takes value $\delta(1-A) /[2-2 \delta(1-A)]>0$ at $\beta=1$. Hence, a unique value $\beta^{\prime \prime \prime}$ exists such that $\varphi_{0} \leq \varphi_{01}^{*}$ if and only if $\beta \leq \beta^{\prime \prime \prime}$. QED.

\section{References}

Abreu, D., "On the Theory of Infinitely Repeated Games with Discounting " Econometrica (56), 1988, pp. 383-396.

Aubert, C., Rey, P., and Kovacic, W. E., "The Impact of Leniency and Whistle-Blowing Programs on Cartels" International Journal of Industrial Organization (24), 2006, pp. 1241-1266.

Bryant, P. And Eckard, E. Woodrow, "The Probability of Getting Caught", The Review of Economics and Statistics (73), August 1991, pp. 531-536.

Bernheim, D. And Whinston, M.D., "Multimarket Contact and Collusive Behavior," RAND Journal of Economics (21), Spring 1990, pp. 1-26.

Choi, J. P. and Gerlach, H., "International Antitrust Enforcement and Multi-market Contact", CESifo Working Paper No. 2599, available at http://ssrn.com/abstract=1368668, 2009a.

Choi, J. P. And Gerlach, H., "Multi-Market Collusion with Demand Linkages and Antitrust Enforcement", CESifo Working Paper No. 2632, available at http://ssrn.com/abstract =1396614, 2009b.

Connor, J. M., "Cartels and Antitrust Portrayed: Numbers, Size, and Location: Private International Cartels", available at http://ssrn.com/abstract=1367843, 2009.

Hammond, S., "Beating Cartels At Their Own Game - Sharing information in the fight against cartels", Presentation at the Inaugural Symposium on Competition Policy in Japan, Tokyo, available at www.justice.gov/atr/public/speeches/201614.pdf, 2003.

Harrington, J. E., "Optimal Corporate Leniency Programs", Journal of Industrial Economics (56), 2008, pp. 215-246.

ICPAC RePort, International Competition Policy Advisory Committee Report, US DOJ Antitrust Division, available at http://www.justice.gov/atr/icpac/finalreport.htm, 2000.

Miller, N. H., "Strategic Leniency and Cartel Enforcement", American Economic Review (99), 2009, pp. $750-768$. 
Motta, M. And Polo, M., "Leniency Programs and Cartel Prosecution" International Journal of Industrial Organization (21), 2003, pp. 347-379.

OECD, "Hard Core Cartels", OECD Report (Paris), 2003.

Spagnolo, G., "Leniency and Whistleblowers in Antitrust", in: Handbook of Antitrust Economics, Paolo Buccirossi, editor. MIT Press, 2008. 


\section{CESifo Working Paper Series}

for full list see www.cesifo-group.org/wp

(address: Poschingerstr. 5, 81679 Munich, Germany, office@cesifo.de)

2941 Peter Debaere, Holger Görg and Horst Raff, Greasing the Wheels of International Commerce: How Services Facilitate Firms' International Sourcing, February 2010

2942 Emanuele Forlani, Competition in the Service Sector and the Performances of Manufacturing Firms: Does Liberalization Matter?, February 2010

2943 James M. Malcomson, Do Managers with Limited Liability Take More Risky Decisions? An Information Acquisition Model, February 2010

2944 Florian Englmaier and Steve Leider, Gift Exchange in the Lab - It is not (only) how much you give ..., February 2010

2945 Andrea Bassanini and Giorgio Brunello, Barriers to Entry, Deregulation and Workplace Training: A Theoretical Model with Evidence from Europe, February 2010

2946 Jan-Emmanuel De Neve, James H. Fowler and Bruno S. Frey, Genes, Economics, and Happiness, February 2010

2947 Camille Cornand and Frank Heinemann, Measuring Agents' Reaction to Private and Public Information in Games with Strategic Complementarities, February 2010

2948 Roel Beetsma and Massimo Giuliodori, Discretionary Fiscal Policy: Review and Estimates for the EU, February 2010

2949 Agnieszka Markiewicz, Monetary Policy, Model Uncertainty and Exchange Rate Volatility, February 2010

2950 Hans Dewachter and Leonardo Iania, An Extended Macro-Finance Model with Financial Factors, February 2010

2951 Helmuth Cremer, Philippe De Donder and Pierre Pestieau, Education and Social Mobility, February 2010

2952 Zuzana Brixiová and Balázs Égert, Modeling Institutions, Start-Ups and Productivity during Transition, February 2010

2953 Roland Strausz, The Political Economy of Regulatory Risk, February 2010

2954 Sanjay Jain, Sumon Majumdar and Sharun W. Mukand, Workers without Borders? Culture, Migration and the Political Limits to Globalization, February 2010

2955 Andreas Irmen, Steady-State Growth and the Elasticity of Substitution, February 2010

2956 Bengt-Arne Wickström, The Optimal Babel - An Economic Framework for the Analysis of Dynamic Language Rights, February 2010 
2957 Stefan Bauernschuster and Helmut Rainer, From Politics to the Family: How Sex-Role Attitudes Keep on Diverging in Reunified Germany, February 2010

2958 Patricia Funk and Christina Gathmann, How do Electoral Systems Affect Fiscal Policy? Evidence from State and Local Governments, 1890 to 2005, February 2010

2959 Betsey Stevenson, Beyond the Classroom: Using Title IX to Measure the Return to High School Sports, February 2010

2960 R. Quentin Grafton, Tom Kompas and Ngo Van Long, Biofuels Subsidies and the Green Paradox, February 2010

2961 Oliver Falck, Stephan Heblich, Alfred Lameli and Jens Suedekum, Dialects, Cultural Identity, and Economic Exchange, February 2010

2962 Bård Harstad, The Dynamics of Climate Agreements, February 2010

2963 Frederick van der Ploeg and Cees Withagen, Is There Really a Green Paradox?, February 2010

2964 Ingo Vogelsang, Incentive Regulation, Investments and Technological Change, February 2010

2965 Jan C. van Ours and Lenny Stoeldraijer, Age, Wage and Productivity, February 2010

2966 Michael Hoel, Climate Change and Carbon Tax Expectations, February 2010

2967 Tommaso Nannicini and Roberto Ricciuti, Autocratic Transitions and Growth, February 2010

2968 Sebastian Brauer and Frank Westermann, A Note on the Time Series Measure of Conservatism, February 2010

2969 Wolfram F. Richter, Efficient Education Policy - A Second-Order Elasticity Rule, February 2010

2970 Tomer Blumkin, Yoram Margalioth and Efraim Sadka, Taxing Children: The Redistributive Role of Child Benefits - Revisited, February 2010

2971 Chang Woon Nam and Georg Wamser, Application of Regionally Varying Additionality Degrees in the Practice of EU Cohesion Policy, February 2010

2972 Ali Bayar, Frédéric Dramais, Cristina Mohora, Masudi Opese and Bram Smeets, Modeling Russia for Climate Change Issues, February 2010

2973 Magnus Söderberg, Informal Benchmarks as a Source of Regulatory Threat in Unregulated Utility Sectors, March 2010

2974 Piotr Wdowiński and Marta Malecka, Asymmetry in Volatility: A Comparison of Developed and Transition Stock Markets, March 2010 
2975 Frans van Winden, Michal Krawczyk and Astrid Hopfensitz, Investment, Resolution of Risk, and the Role of Affect, March 2010

2976 Hyun-Ju Koh and Nadine Riedel, Do Governments Tax Agglomeration Rents?, March 2010

2977 Johann K. Brunner and Susanne Pech, Optimum Taxation of Bequests in a Model with Initial Wealth, March 2010

2978 Guglielmo Maria Caporale and Nicola Spagnolo, Stock Market Integration between three CEECs, Russia and the UK, March 2010

2979 Florian Englmaier, Ales Filipi and Ravi Singh, Incentives, Reputation and the Allocation of Authority, March 2010

2980 Konstantinos Angelopoulos, George Economides and Apostolis Philippopoulos, What is the Best Environmental Policy? Taxes, Permits and Rules under Economic and Environmental Uncertainty, March 2010

2981 Frederick van der Ploeg, Rapacious Resource Depletion, Excessive Investment and Insecure Property Rights, March 2010

2982 Wolfram F. Richter and Christoph Braun, Efficient Subsidization of Human Capital Accumulation with Overlapping Generations and Endogenous Growth, March 2010

2983 Francesco Cinnirella, Marc Piopiunik and Joachim Winter, Why Does Height Matter for Educational Attainment? Evidence from German Pre-Teen Children, March 2010

2984 Bernard Van Praag, Well-being Inequality and Reference Groups - An Agenda for New Research, March 2010

2985 Francesca Barion, Raffaele Miniaci, Paolo M. Panteghini and Maria Laura Parisi, Profit Shifting by Debt Financing in Europe, March 2010

2986 Alexander Haupt and Magdalena Stadejek, The Choice of Environmental Policy Instruments: Energy Efficiency and Redistribution, March 2010

2987 John Komlos and Marek Brabec, The Trend of BMI Values among US Adults, March 2010

2988 Emanuele Massetti and Lea Nicita, The Optimal Climate Policy Portfolio when Knowledge Spills across Sectors, March 2010

2989 Helmut Rainer and Thomas Siedler, Family Location and Caregiving Patterns from an International Perspective, March 2010

2990 Toru Kikuchi and Ngo Van Long, A Simple Model of Service Offshoring with Time Zone Differences, March 2010 
2991 Assaf Razin, Efraim Sadka and Benjarong Suwankiri, Migration and the Welfare State: Dynamic Political-Economy Theory, March 2010

2992 Bård Harstad, Buy Coal! Deposit Markets Prevent Carbon Leakage, March 2010

2993 Axel Dreher, Stephan Klasen, James Raymond Vreeland and Eric Werker, The Costs of Favoritism: Is Politically-driven Aid less Effective?, March 2010

2994 Sven Neelsen and Thomas Stratmann, Effects of Prenatal and Early Life Malnutrition: Evidence from the Greek Famine, March 2010

2995 Claude Hillinger and Bernd Süssmuth, The Quantity Theory of Money: An Assessment of its Real Linchpin Prediction, March 2010

2996 Matthew M. Chingos and Martin R. West, Do More Effective Teachers Earn More Outside of the Classroom?, March 2010

2997 Laurence Jacquet and Dirk Van de gaer, A Comparison of Optimal Tax Policies when Compensation or Responsibility Matter, March 2010

2998 Valentina Bosetti, Carlo Carraro, Romain Duval and Massimo Tavoni, What Should we Expect from Innovation? A Model-Based Assessment of the Environmental and Mitigation Cost Implications of Climate-Related R\&D, March 2010

2999 Scott Alan Carson, Nineteenth Century Stature and Family Size: Binding Constraint or Productive Labor Force?, March 2010

3000 Jukka Pirttilä and Ilpo Suoniemi, Public Provision, Commodity Demand and Hours of Work: An Empirical Analysis, March 2010

3001 Bertrand Candelon and Franz C. Palm, Banking and Debt Crises in Europe: The Dangerous Liaisons?, March 2010

3002 Joan Costa-i-Font and Marin Gemmill-Toyama, Does Cost Sharing really Reduce Inappropriate Prescriptions?, March 2010

3003 Scott Barrett, Climate Treaties and Backstop Technologies, March 2010

3004 Hans Jarle Kind, Tore Nilssen and Lars Sørgard, Price Coordination in Two-Sided Markets: Competition in the TV Industry, March 2010

3005 Jay Pil Choi and Heiko Gerlach, Global Cartels, Leniency Programs and International Antitrust Cooperation, March 2010 